Canadian Science Publishing

Canadian Journal of Forest Research Revue canadienne de recherche forestière

\title{
Model-based evaluation of sediment control in a drained peatland forest after ditch network maintenance
}

\begin{tabular}{|c|c|}
\hline Journal: & Canadian Journal of Forest Research \\
\hline Manuscript ID & cjfr-2017-0269.R1 \\
\hline Manuscript Type: & Article \\
\hline Date Submitted by the Author: & 20-Nov-2017 \\
\hline Complete List of Authors: & $\begin{array}{l}\text { Haahti, Kersti; Aalto University School of Engineering, Department of Built } \\
\text { Environment } \\
\text { Nieminen, Mika; Natural Resources Institute Finland (Luke) } \\
\text { Finér, Leena; Natural Resources Institute Finland (Luke), Joensuu } \\
\text { Marttila, Hannu; University of oulu, Water Resources and Environmental } \\
\text { Engineering Research Unit } \\
\text { Kokkonen, Teemu; Aalto University School of Engineering, Department of } \\
\text { Built Environment } \\
\text { Leinonen, Antti; Finnish Forest Center } \\
\text { Koivusalo, Harri; Aalto University School of Engineering, Department of } \\
\text { Built environment }\end{array}$ \\
\hline Keyword: & $\begin{array}{l}\text { erosion modeling, forestry, hydrological modeling, peatland drainage, } \\
\text { water protection }\end{array}$ \\
\hline $\begin{array}{r}\text { Is the invited manuscript for } \\
\text { consideration in a Special } \\
\text { Issue? : }\end{array}$ & N/A \\
\hline
\end{tabular}




\title{
Model-based evaluation of sediment control in a drained peatland forest after ditch network maintenance
}

\author{
Kersti Haahti ${ }^{a}$, Mika Nieminen ${ }^{\text {b }}$, Leena Finér ${ }^{c}$, Hannu Marttila ${ }^{d}$, Teemu Kokkonen ${ }^{a}$, Antti \\ Leinonen $^{\mathrm{e}}$, and Harri Koivusalo ${ }^{\mathrm{a}}$
}

${ }^{a}$ Aalto University School of Engineering, Department of Built Environment, Espoo, Finland. emails: kersti.haahti@aalto.fi, teemu.kokkonen@aalto.fi, harri.koivusalo@aalto.fi

${ }^{\mathrm{b}}$ Natural Resources Institute Finland, Helsinki, Finland. email: mika.nieminen@luke.fi

${ }^{\mathrm{c}}$ Natural Resources Institute Finland, Joensuu, Finland. email: leena.finer@luke.fi

${ }^{\mathrm{d}}$ University of Oulu, Water Resources and Environmental Engineering Research Unit, Oulu, Finland. email: hannu.marttila@,oulu.fi

${ }^{\mathrm{e}}$ Finnish Forest Center, Kajaani, Finland. email: antti.leinonen@metsakeskus.fi

Corresponding author: email: kersti.haahti@aalto.fi, tel. +358415475607 P.O. Box 15300, FI-00076 Aalto, Finland. 


\begin{abstract}
Reducing the strain on water bodies caused by sediment loads released after ditch network maintenance (DNM) is addressed in operational peatland forestry by implementing sediment control structures in ditches. This study evaluates computationally alternative sediment control scenarios in a 5.2 ha deep peat site in Eastern Finland. Coupled to a distributed hydrological model, peat erosion and transport in the ditches were simulated for the first year after DNM with 15 scenarios consisting of individual structures (e.g., sedimentation ponds) and their combinations. One scenario represented the prevailing conditions with a V-notch weir at the catchment outlet. All scenarios were evaluated against a baseline scenario, where no structures affected the catchment sediment processes. The results suggested that bed erosion can be efficiently prevented with breaks in cleaning and structures ponding water. It was proven less efficient to trap already eroded material with sedimentation ponds and pits. The structures raising ditch water level had limited effects on water table levels in the strips between ditches, plausibly not impairing tree growth. The presented process-based modeling provided a yet unexplored approach to comprehensively evaluate alternatives for sediment control, which is highly needed to address the gap between existing scientific knowledge and operational peatland forestry practices.
\end{abstract}

Keywords: erosion modeling; forestry; hydrological modeling; peatland drainage; water protection 


\section{Introduction}

Increased suspended sediment (SS) loads originating from peatland drainage are widely recognized (e.g., Robinson and Blyth 1982, Prévost et al. 1999, Pavey et al. 2007) and the resulting strain on receiving water bodies raises concern (e.g., Ramchunder et al. 2009). In the boreal region, peat soils have been drained mainly for forestry, agriculture, and peat harvesting (Päivänen and Hånell 2012). Controlling sediment loads from these areas has been addressed, e.g., by flow control structures or ditch-blocking (Amatya et al. 2003, Holden et al. 2007), wetland buffers (Nieminen et al. 2005, Hansen et al. 2013), and sedimentation ponds (Joensuu et al. 1999, Samson-Dô 2015).

In forestry-drained sites, SS loads return close to pre-drainage conditions after the effect of initial first-time drainage levels down (Ahtiainen and Huttunen 1999, Prévost et al. 1999). In the Fennoscandian conditions, however, ditch network maintenance (DNM) is typically required every 20-40 years (Hökkä et al. 2000). DNM reactivates ditch erosion processes increasing SS loads again, with major exports during the first year (Manninen 1998, Joensuu et al. 2002, Hansen et al. 2013). In Finland and Sweden, where drained peatland forests cover about 6.5 Mha (Päivänen and Hånell 2012), planning sediment control along with DNM is promoted by guidelines for forestry water protection (e.g., Ring et al. 2008, Vanhatalo et al. 2015). These guidelines list sedimentation ponds and pits, peak runoff control (PRC), breaks in cleaning, submerged weirs, and wetland buffers as structures for controlling water quality. Despite their routine-like implementation in operational peatland forestry, scientific knowledge on their efficiency in controlling sediment loads is incomplete.

Experimental studies on the efficiency of the recommended structures are mainly restricted to sedimentation ponds, PRC and wetland buffers. Based on a field study of 37 catchments with sedimentation ponds, Joensuu et al. (1999) reported an average reduction of $18 \%$ in SS concentrations during the first year after DNM. Low reductions were associated with sites with deep peat or finetextured mineral subsoils (Joensuu et al. 1999). Correspondingly, Manninen (1998) reported a 20\% reduction immediately after DNM for a pond in deep peat, but no further retention later. Large variation in treatment performance for ponds in peat harvesting areas have also been reported, e.g., 41- 
68\% (Kløve 2000) and -379-85\% (Samson-Dô 2015). Among structures aiming to retain SS, wetland buffers have been acknowledged as highly efficient (Sallantaus et al. 1998, Nieminen et al. 2005). However, buffer construction is restricted to areas, where sloping land enables high water table only in the buffer itself, without raising water table and disturbing tree growth upstream. Hence, other sediment control structures implemented in ditch networks are used in operational forestry much more frequently than wetland buffers.

Compared to sedimentation ponds and wetland buffers, for which sediment retention can be quantified as the difference between sediment input and output, determining the efficiency of PRC requires a more complex experimental setup. PRC structures, consisting of a set of throughflow pipes, are designed to retain runoff during peak flows with the aim of decreasing erosion and enhancing deposition. Amatya et al. (2003) applied a paired catchment approach and reported annual reductions of $0.3-89 \%$ over five years. In a corresponding setup in Finland by Marttila and Kløve (2010), sediment exports were reduced by $81-90 \%$. Similar high reductions have been reported in peat harvesting (e.g, Kløve 2000). Furthermore, Marttila et al. (2010) studied PRC in five forestry catchments and reported efficient runoff retention, but were unable to quantify SS load reduction due to infrequent sampling.

Experimental approaches in this context are challenged by the highly dynamic nature of SS transport, as well as varying meteorological conditions and site characteristics, which complicate the quantification and comparison of the efficiency of different structures and their combinations. This is especially true for structures scattered within the ditch network. Such structures include, e.g., breaks in cleaning and sedimentation pits, which despite the lack of scientific evidence on their performance, are routinely implemented in operational forestry. A comprehensive evaluation of sediment control alternatives is much needed to enhance operational level guidance in order to reduce the strain on receiving water bodies. Process-based modeling of ditch network flow and SS transport (Haahti et al. 2016a) supports such evaluation as it enables the explicit representation of structures within the ditches. Coupled to a spatially distributed hydrological model (Haahti et al. 2016b), it further enables 
the assessment of drainage conditions in the strips between ditches. Although impaired drainage conditions due to structures ponding water raise concern in operational forestry, Hökkä et al. (2011) observed no significant water table level rise close to a PRC structure in a Finnish site. In contrast, Amatya et al. (2003) reported an increase of $7 \mathrm{~cm}$ in water table level due to PRC in a site in North Carolina.

The objective of this study is to apply model scenarios to evaluate sediment control practices carried out in operational peatland forestry alongside DNM. To the authors' knowledge, this is the first study to attempt the quantitative assessment and comparison of variable sediment control alternatives in such circumstances. The study builds upon the earlier work of Haahti et al. (2016a, 2016b) comprising spatially distributed modeling of hydrological processes, peat erosion and transport in a 5.2 ha forestry-drained peatland catchment after DNM. The work was extended in this study to simulate catchment hydrology and sediment transport after DNM with 14 sediment control scenarios derived from forestry guidelines (e.g., Vanhatalo et al. 2015) featuring individual structures and their combinations. The study was limited to the first year after DNM to demonstrate the performance of sediment control structures during the time of the highest loads (e.g., Joensuu et al. 2002). One additional scenario represented the prevailing conditions, with a V-notch weir at the catchment outlet, which was validated against the field data by Haahti et al. (2016a). All scenarios were compared against a baseline scenario, where no structures affected the catchment sediment processes. Based on the simulation results, we aimed to supplement experimentally gained knowledge on sediment control structures and to derive implications to operational level guidance by assessing 1) the overall efficiencies of the alternative scenarios, 2) the processes controlling the efficiency of different structures over the first year, and 3) the impacts on drainage conditions.

\section{Study site}

\subsection{Description}

The study site comprises a 5.2 ha Scots pine dominated drained peatland catchment (Fig. 1c) in 
Eastern Finland (Fig. 1a). The long-term (1981-2010) annual mean values for regional air temperature and precipitation were $2.3^{\circ} \mathrm{C}$ and $591 \mathrm{~mm}$, respectively. The studied catchment is part of a larger Koivupuro catchment (Fig. 1b), which was initially drained in 1983 and DNM was conducted in August 2011. During DNM, the ditches were dug to a depth of $1 \mathrm{~m}$ and a width of about $2 \mathrm{~m}$. Only about $20 \%$ of the ditches in the studied catchment reached the mineral soil below the peat layer (Fig. 1c).

After DNM, the studied catchment was intensively monitored, including e.g. discharge, water table depth, ditch water depth, and a variety of erosion related measurements (see Haahti et al. 2016a, 2016b). For monitoring discharge, a V-notch weir was installed at the catchment outlet during DNM. Flow over the V-notch followed the stage-discharge relationship:

$$
Q=1.381\left(h-h_{\text {weir }}\right)^{2.5}
$$

where $Q$ is the discharge $\left(\mathrm{m}^{3} / \mathrm{s}\right), h$ is the upstream water depth $(\mathrm{m})$, and $h_{\text {weir }}$ is the distance between the ditch bed and the bottom of the V-notch $(0.27 \mathrm{~m})$.

\subsection{Earlier modeling}

\subsubsection{Integrated hydrological modeling}

This study builds upon earlier studies, which have focused on modeling hydrology (Haahti et al. 2016b) and sediment transport (Haahti et al. 2016a) in the same catchment (Fig. 1c). In the study by Haahti et al. (2016b), the hydrological FLUSH model (Warsta et al. 2013) was extended with a description for ditch network flow. In short, the model computes energy-balance-based snow accumulation and melt, overland flow (2-D), unsaturated and saturated subsurface flow (3-D), and flow in a ditch network (1-D). Simulating ditch flow enables the representation of the interaction between ditch water level and soil moisture conditions. Canopy processes were accounted for by computing model inputs (transpiration demand, precipitation reaching the ground surface, and other meteorological variables below the forest canopy) by a separate forest hydrological model, FEMMA (Koivusalo et al. 2006).

Haahti et al. (2016b) calibrated and validated the model against field measurements obtained over 
frost-free periods in 2012 and 2013. The hydrological simulations were further extended over winter periods by Haahti et al. (2016a) resulting in a two-year-long simulation period following DNM. The first year, which is the focus of the current study, was exceptionally rainy $(939 \mathrm{~mm})$ and snow covered the ground from December to early May. The two-week snowmelt period was followed by a rainy summer with runoff as the dominant water balance component (Haahti et al. 2016b).

The simulations (Haahti et al. 2016a, 2016b) were conducted with a $5 \times 5 \mathrm{~m}^{2}$ horizontal spatial resolution. In the vertical direction, the 2-m-deep soil profile was discretized into 18 layers (thickness 0.05 to $0.25 \mathrm{~m})$. The ditches were discretized with a maximum distance step of $10 \mathrm{~m}$. The crosssection of the 1-m-deep ditches resembled a semicircle with a 0.35 -m-wide flat bottom. Calibration against measurements of discharge, water table depth, and ditch water depth led to a horizontally highly conductive surface peat layer, and a description of ditch flow resistance (Manning's $n$ ) as a function of flow rate (Haahti et al. 2016b).

\subsubsection{Modeling sediment transport}

Haahti et al. (2016a) further developed the model to describe peat erosion and transport processes in the cleaned ditch network. The model computes bed erosion, rain-induced erosion from ditch banks, deposition including the effect of flocculation, and consolidation of the bed. Bed erosion occurs above a critical bed shear stress level, which depends on the consolidation time of the bed surface layer. Hereby, freshly deposited material erodes more readily than a bed, which has had time (3-5 days) to consolidate (see Lin and Wu 2013). Rain-induced erosion of the ditch banks depends on the exposed bank surface area and the rainfall intensity. The effect of flocculation is accounted for in the description of deposition, where settling velocity is related to concentration.

Haahti et al. (2016a) simulated the two years after DNM increasing the complexity of the sediment transport model stepwise to understand the role of different processes. For each step, the sediment transport model was run using 100 random parameter sets sampled over credible parameter ranges. The resulting ranges of model outcomes were evaluated against observed SS loads and concentrations (turbidity-based), spatially measured bed elevation changes, and sediment mass exchange with ditch 
banks. Model calibration resulting in a single parameter set was not attempted by Haahti et al. (2016a) because of the uncertainties inherent especially in the SS concentration data.

\section{Modeling approach to investigate sediment control}

\subsection{Dimensions of structures and their parameterization}

In the following sections, we present the practical guidelines related to the five investigated structures (Päivinen et al. 2011, Joensuu et al. 2012, Vanhatalo et al. 2015), and the selected dimensioning for each structure. The implementation of the structures in the model included changing the cross-section, adding extra nodes to refine the longitudinal bottom elevation profile, and adjusting some of the flow or erosion related parameters. Buffer wetlands were left out of this study as they require sloping land, often unavailable in peatland-dominated catchments, and are therefore rarely implemented in operational forestry.

\subsubsection{Sedimentation ponds and pits}

Sedimentation ponds are typically dimensioned based on the mean spring maximum discharge estimated using the method by Seuna (1983). Following the approach by Joensuu et al. (2012), the water surface area of the pond is determined by dividing this discharge by the settling velocity $(1 \mathrm{~m} / \mathrm{h}$ for fine sediments). The length, width, and depth of the pond are subsequently chosen so that the width to length ratio is between 1:3 and 1:7, the flow velocity does not exceed $1 \mathrm{~cm} / \mathrm{s}$, and the pond water volume ranges from 2 to $5 \mathrm{~m}^{3} /$ catchment-ha. The typical side slope used for the ponds is 1:0.5 (height to width ratio). The pond dimensions obtained for our catchment based on these guidelines are shown in Fig. 2a.

In contrast to significantly larger sedimentation ponds, the purpose of small-sized sedimentation pits is to trap sediments eroded from the feeder ditches, especially during and immediately after DNM (Vanhatalo et al. 2015). Sedimentation pits were characterized in the model by a trapezoidal crosssection (Fig. 2b). The dimensions were adjusted to the recommended storage volume of $1-2 \mathrm{~m}^{3}$ (Vanhatalo et al. 2015). 


\subsubsection{Breaks in cleaning}

To prevent erosion in steep ditch sections, guidelines suggest to leave up to a few tens of meters of such sections uncleaned during DNM (e.g., Vanhatalo et al. 2015). We assumed that the elevation of the ditch bed before cleaning was $0.2 \mathrm{~m}$ higher than after cleaning and implemented 3-20-m-long uncleaned sections in the scenarios (Fig. 2c). The intact vegetation in these sections was expected to slow down flow and protect the ditch banks from erosion. Hereby, Manning's flow resistance was limited by a minimum of $n=0.5$ in the uncleaned sections, while in other parts of the ditch network it would decrease to $n \approx 0.1$ during high flow events. Other parameters changing along the break in cleaning were the erodibility of the banks (set to zero) and the consolidation time of the bed surface layer at initial conditions. The disturbed conditions after DNM in the cleaned ditches are represented in the model by a surface layer with an initial consolidation time of zero (see Haahti et al. 2016a). Along a break in cleaning, however, the bed remains undisturbed and therefore the bed was described as fully consolidated at initial conditions.

\subsubsection{Submerged weir}

Submerged weirs constructed of stones or wood are recommended when a ditch section shows signs of considerable erosion risk already before DNM (Päivinen et al. 2011). Another purpose is to improve the efficiency of a sedimentation pond by installing a submerged weir at its outlet (Vanhatalo et al. 2015). Submerged weirs were implemented in the model in two ways depending on whether they were located within the network or at its outlet.

Within the network, the submerged weir was described as a short elevated section filled to the height of the weir ( $h_{\text {weir }}$, Fig. $\left.2 \mathrm{~d}\right)$. The material used to construct submerged weirs should prevent flow from washing the weir away, which was translated to the model by defining zero bed erodibility at the weir.

When the weir was located at the network outlet, it was defined as a boundary condition expressed by the equation for flow over a broad-crested weir (Hamill 2001): 


$$
Q=C \sqrt{2 g} B_{\text {weir }}\left(h-h_{\text {weir }}\right)^{1.5}
$$

where $Q$ is discharge $\left(\mathrm{m}^{3} / \mathrm{s}\right), C$ is the weir discharge coefficient $(0.36), g$ is gravitational acceleration

$\left(\mathrm{m} / \mathrm{s}^{2}\right), B_{\text {weir }}$ is the width of the weir surface $(\mathrm{m}), h$ is the upstream water depth $(\mathrm{m})$, and $h_{\text {weir }}$ is the height of the weir from the ditch bed (m).

\subsubsection{Peak runoff control (PRC)}

PRC enables temporary storage of runoff in the ditch network during high flow events decreasing erosion and increasing deposition within the ditch network (Vanhatalo et al. 2015). Detention is typically achieved with two control pipes as shown in Fig. 3a (Marttila et al. 2010). Theoretically, the discharge through the structure follows the equation for flow through a small orifice (Hamill 2001):

$$
Q=C A \sqrt{2 g H}
$$

where $C$ is the loss coefficient (0.5 according to Marttila and Kløve (2010)), $A$ is the cross-sectional area of the pipe $\left(\mathrm{m}^{2}\right)$, and $H$ is the water depth above the pipe inlet (m). Based on equation (3), a stagedischarge rating curve can be established for the structure. Its form depends on the number of pipes, their installation heights, and diameters. In the setup of two pipes, the upper pipe prevents overflow during exceptionally high flows, and the lower pipe retains average high flows. The overflow pipe should be installed 30-40 cm below the surrounding soil surface elevation (Joensuu et al. 2012). Accordingly, we selected two-pipe setup that ensured flow retention up to the estimated mean spring maximum discharge, 10.9 l/s (Fig. 3b). The rating curve (Fig. 3b) was used in the model as the downstream boundary condition at the catchment outlet.

\subsection{Simulated scenarios}

To assess the efficiency of different sediment control structures and their combinations in reducing SS loads, altogether 16 scenarios were computed (Fig. 4). As the V-notch weir installed for discharge monitoring at the catchment outlet (Fig. 4b) acted as a flow control structure by ponding water (Haahti et al. 2016b), this setup could not be used as a baseline for the evaluation of sediment control. For this reason, we produced a hypothetical baseline scenario, where no structures affected the catchment sediment processes. This was achieved by moving the $\mathrm{V}$-notch weir (boundary condition) about $90 \mathrm{~m}$ 
downstream and lowering its bottom elevation to $h_{\text {weir }}=0.1 \mathrm{~m}$ (eq. (1); Fig. 4a). A total of 14 sediment control scenarios (Fig. 4c-p) along with the scenario corresponding to the prevailing conditions (Fig. 4b) were compared against this baseline scenario (Fig. 4a).

In the first sediment control scenario, the sedimentation pond presented in Fig. 2a was implemented before the catchment outlet (Fig. 4c). The pond was further combined with a 0.3 -m-high submerged weir (Fig. 4j) and PRC (Fig. 4k) following guideline recommendations (e.g., Päivinen et al. 2011). PRC was also implemented by itself at the catchment outlet (Fig. 4g), and combined with a sedimentation pit (Fig. 4o). A pit or a pond before the PRC structure is recommended to avoid blockage of the lower pipe due to the accumulation of deposits (e.g., Joensuu et al. 2012).

Sedimentation pits are recommended in feeder ditches about $5 \mathrm{~m}$ before all junctions and additionally every 50-100 m along the feeder ditches (Vanhatalo et al. 2015). We selected two scenarios with pits; Fig. 4d with only four pits, and Fig. 4h following the guidelines. Enhancing the trapping efficiency of pits by leaving a break in cleaning after them (Fig. 4l) is also recommended (e.g., Joensuu et al. 2012). As an alternative, we also produced a scenario with 10-m-long breaks in cleaning (Fig. 4i) in the same locations as the pits and breaks in Fig. 41.

The simulations by Haahti et al. (2016a) revealed that the highest risk for bed erosion was in the downstream end of the second ditch counting from west to east. To avoid erosion in this section, scenarios with a 20-m-long break in cleaning (Fig. 4e) and a 0.5-m-high submerged weir (Fig. 4f), as well as combining these with sedimentation pits (Figs. $4 \mathrm{~m}, \mathrm{n}$ ) were evaluated. The final scenario aimed both to prevent erosion at the riskiest section with a break in cleaning, and to trap transported SS before the outlet with a pond-PRC combination (Fig. 4p).

\subsection{Simulations and evaluation of results}

All scenarios in Fig. 4 were simulated for the first year after DNM from 17-Aug-2011 to 17-Aug2012 using hourly input data. First, an initial run was computed for each scenario to obtain soil hydrological conditions and flow conditions in the ditch network. In these initial runs, the SS transport submodel was inactivated. Subsequently, only the network flow and SS transport submodels were run 
for each scenario with the 100 parameter sets sampled by Haahti et al. (2016a). In the SS transport submodel, descriptions for all erosion and sediment transport processes studied in Haahti et al. (2016a) were activated (see section 2.2.2.). For each scenario, inflow to the ditches and its spatial distribution along the network nodes were obtained from the initial run and were used as inputs in the subsequent 100 model runs. Hereby, we avoided rerunning the computationally demanding soil hydrological submodels for hundreds of times.

The evaluation of the results was divided into two parts. Firstly, we investigated the effect of individual structures (Figs. 4b-g) on flow conditions in the ditch network (discharge at the outlet, flow velocity, and ditch water level), and their feedback to the water table levels in the strips between ditches. As this only concerned the hydrological model outputs (initial run), we had a single model result for each scenario. Investigating these hydrological variables was approached by producing frequency distributions for each variable including variable values over spatial units (network nodes or soil columns) and all computed time-steps (Table 1). Similarly, distributions depicting changes in frequencies compared to the Baseline scenario were produced. For flow velocity and ditch water level, we additionally produced frequency distributions at the location of the structures (Table 1).

Secondly, we investigated the SS processes that were addressed as output ranges available from the 100 SS transport model runs for each scenario. For each scenario, we compared SS load, the amount of bed and bank erosion, and sediment deposition to the corresponding values computed for the Baseline scenario. Additionally, we calculated SS load reductions for each scenario. The SS load includes the excess SS load, which originates from modeled erosion processes, and the background load, which is the same for all scenarios and parameterizations (inflow $\times 2 \mathrm{mg} / \mathrm{l}$ ). The sediment control efficiency of each scenario over time was further evaluated by producing SS load reductions at two-week time intervals in order to elucidate the temporal dynamics of retention processes. 


\section{Results}

\subsection{Flow conditions in ditches and water table levels}

Adding structures in the ditches (Figs. 4b-g) altered flow conditions in the ditch network and affected the water table levels in the strips between ditches (Fig. 5). Most structures (Figs. 5a,e,i,m,q) had minor effects on the distribution of outlet discharge. However, PRC clearly altered discharge by cutting off the highest peaks and extending the recession of flow events, which can be seen as more frequent middle range discharge values (Fig. 5u). Flow conditions within the network were affected similarly by the V-notch and the PRC structure; velocity decreased (Figs. 5b,v) and ditch water level increased (Figs. 5c,w). These changes were not limited to the structure location, which indicates that the effect of these structures extended upstream. PRC raised the water level in the ditch up to $0.3 \mathrm{~m}$ below the surrounding soil surface (Fig. 5w), i.e. the level of the overflow pipe (Fig. 3b).

The pond increased the frequency of low flow velocities, and the velocity of $0.03 \mathrm{~m} / \mathrm{s}$ was never exceeded in the pond (Fig. 5f). Similarly, within the pits velocities were low, but contrary to expectations higher velocities at other locations in the ditch network became more frequent (Fig. $5 \mathrm{j}$ ). Closer inspection revealed these higher velocities occurred before the pits. The inlet points of pits were at a higher elevation than their outlet points, which created high velocities over the inlet edge of the pits.

The break in cleaning and the submerged weir both increased ditch water level along the structure (Figs. 5o,s), as the ditch bottom level was elevated at their locations (Figs. 2c,d). Flow velocities were, however, differently affected; the break prevented the highest velocities (Fig. 5n), while the submerged weir led to more frequent high velocities (Fig. 5r). Higher flow resistance along the break maintained lower velocities, but still velocities $>0.1 \mathrm{~m} / \mathrm{s}$ occurred. For the submerged weir all velocities $>0.2 \mathrm{~m} / \mathrm{s}$ occurred on the weir (Fig. 5r), which will not lead to erosion in the model as the weir was described as non-eroding.

The raised ditch water levels caused by the structures (Figs. 5c,o,s,w) were reflected in the distributions of water table within the forested strip, with higher levels becoming more frequent (Figs. 
5d,p,t,x). Fig. 6 further illustrates the spatial distribution of the changes in water table level and ditch water level. The scale bars reveal that the changes in water table level were about three orders of magnitude smaller than the changes in ditch water levels, which was caused by the low hydraulic conductivity of the deeper peat layers (see Haahti et al. 2016b). With all structures except PRC, the changes in water table level were more pronounced in the left panes, illustrating the mean summertime conditions, than in the right panes, showing the conditions during a rainfall event on 7-Aug-2012 (Fig. 6). The PRC structure differed from the other structures as it only became active during higher flow rates, which caused only short-term ponding in the network during rainfall events (Figs. 6k,1). The pond and pits showed decreased water table level but no notable changes in ditch water level (Figs. 6cf). This resulted from the larger contact area of these structures with the peat soil due to their depth (Figs. 2a,b).

\subsection{Impacts on SS processes}

The median SS load produced for the Baseline scenario was $44 \mathrm{~kg} / \mathrm{ha}$ for the first year after DNM (Fig. 7a). Most of the load was exported during the exceptionally rainy summer (Fig. 7a). All simulated sediment control scenarios decreased SS load except for the scenarios featuring pits only (Fig. 7b, Table 2). The load increase by the Pits 1 and Pits 2 was caused by the increased bed erosion (Fig. 7c), which resulted from the higher flow velocities before the pits.

The $V$-notch decreased SS load notably as its ponding effect (Figs. $5 \mathrm{~b}, \mathrm{c}$ ) reduced bed erosion and enhanced deposition (Figs. 7c,e). The ponding caused by the weir also reduced bank erosion, but only slightly (Fig. 7d) as the exposed bank area decreased due to higher ditch water levels (Fig. 5c). The $P R C$ affected bed erosion and deposition similarly as the $V$-notch, but resulted in a larger overall SS load reduction (Table 2). The $P R C$ had, however, a smaller effect on SS load during the first autumn than the $V$-notch (Fig. 7b). This resulted from the sensitivity of the ditches to erosion immediately after DNM also at lower flow rates, which are not efficiently regulated by the $P R C$ (Fig. $5 \mathrm{u}$ ). The Pond decreased SS load marginally (Fig. 7b, Table 2) by enhancing deposition (Fig. 7e). The Break and the SWeir decreased SS loads mainly by reducing bed erosion (Figs. 7b,c). Among the different single 
structure scenarios, the SWeir was the most efficient decreasing SS load by $16-46 \%$ (Table 2). The Breaks was also efficient in decreasing SS load (Table 2) and was the scenario with the most notable effect on bank erosion (Fig. 7d), although marginal compared to the total amount of bank erosion (Fig. 7a).

Combining structures (Break, SWeir, PRC) with pits (Pit-Break, Pit-SWeir, and Pit-PRC) did not improve SS load reduction (Fig. 7b, Table 2). Adding breaks in clening after the pits (Pits-Breaks) improved sediment control compared to the Pits1 (Fig. 7b). The short breaks in cleaning ensured that flow velocity would not increase before the pits, as in the Pitsl (Fig. 5j). Compared to the Pits-Breaks, the Breaks was more efficient (Fig. 7b, Table 2). Combining a damming structure with the pond (Pond-SWeir and Pond-PRC) improved sediment control compared to the Pond (Fig. 7b, Table 2). Also, the Pond-PRC improved sediment control compared to the scenario without a pond (PRC), but the median reduction increased only by 2 percentage points (Table 2 ). The last combination scenario (Break-Pond-PRC) was the most efficient decreasing SS load by 19-52\% (Table 2).

The temporal variations of the two-week reductions of SS load (Figs. 8c-q) were mostly explained by the magnitude of the loads (Fig. 8b) which in turn were driven by hydrological conditions (Fig. 8a). Many scenarios reached their peak reduction during the snowmelt period (e.g., Figs. 8g,h), which had the highest SS load (Fig. 8b). The undulating reductions during the summer common for many scenarios (e.g., Figs. 8g,h) were also mainly caused by the variability of the SS load (Fig. 8b). The $V$ notch, the Pond and the Pond-SWeir (Figs. 8c,d,k) behaved differently, as they reached their peak reduction immediately after DNM, when high SS concentrations occurred at relatively low flow rates enabling more efficient settling by these structures than at later times. Another feature worth noting was that the breaks in cleaning occasionally increased SS load (Figs. 8f,j,m,n,q). Closer inspection showed that this was caused by the downstream edge of the breaks smoothing out due to erosion, similar to what was observed with the pits. However, SS loads during the times of negative reductions were low (Fig. 8b), which explains why this was not reflected in the overall reductions (Table 2). 


\section{Discussion}

\subsection{Value of modeling for impact assessment}

At the time of DNM, forest managers are faced with a choice between many alternatives for sediment control, comparable to the scenarios of this study (Fig. 4). To date, the scientific community has provided guidance to the operational level by experimentally studying individual structures (e.g., Joensuu et al. 1999, Nieminen et al. 2005, Marttila et al. 2010), however, leaving a large gap between scientific knowledge and operational peatland forestry practices. Comparing alternatives for sediment control has hardly been addressed as studies are often restricted to the evaluation of one control and one treatment site (e.g., Amatya et al. 2003, Marttila and Kløve 2010). Another widely used approach has been to sample the waters above and below a water protection structure (e.g., Nieminen et al. 2005). The challenge in experimental studies comes down to setting up a feasible amount of parallel sites to study alternative structures and their combinations. All sites should be operated with DNM and monitored thereafter. Variable meteorological conditions further pose a risk to a successful experiment, as a dry year producing low SS loads would result in a dataset with little information. Finally, monitoring highly dynamic SS concentrations is challenging (e.g., Marttila et al. 2010). On the account of all these factors, the need for model-based assessments is obvious. As demonstrated in this study, process-based modeling can be applied to meet the objective of comparing and evaluating alternative sediment control practices, and to reach results beyond laborious field experiments. In addition to the overall comparison of scenarios, such an approach provides understanding of the underlying processes controlling the efficiency of different structures, which is a necessity for further development of sediment control.

This study presented a purely scenario-based evaluation of sediment control alternatives, but the modeling work behind this study was strongly linked to field data (Haahti et al. 2016a, 2016b). Applying models to evaluate outcomes of alternative scenarios whether it concerns agricultural practices, climate change, or optimizing forest management (e.g., Vaché et al. 2002, Andréasson et al. 2004, Ahtikoski et al. 2012) has become widely accepted. Nevertheless, modeling always includes 
assumptions and simplifications, which should be considered when evaluating the model outcomes. In the case of our simulations, e.g., the submerged weir was fully watertight and unaffected by erosion, water in the PRC pipe could not freeze (e.g., Marttila et al. 2010), and possible exposure of erosion sensitive mineral subsoil, e.g., in the pond, was not accounted for. It can also be questioned, whether a one-dimensional model is adequate in describing flow patterns in large sedimentation ponds (e.g., Mohammadighavam et al. 2015). Despite these minor deficiencies, we argue that our modeling approach, which has a sound theoretical framework and has gone through validation against field data (Haahti et al. 2016a, 2016b), provides a scientifically-based and cost-effective way to assess alternative sediment control practices with possible implications to operational peatland forestry. However, it should be kept in mind that results presented in this study concerned a single site (5.2 ha) with a deep peat layer and poorly conductive subsoil restricting the generalization of the results. This is highlighted by the fact that the SS load consequent to DNM from the studied site was considerably lower than the average values reported from Finnish sites (Finér et al. 2010), which are affected by the high SS loads from sites with fine-textured mineral subsoil.

\subsection{Implications to operational forestry}

In Finland, the most common structures for sediment control in operational peatland forestry are sedimentation ponds and pits. They have been favored because of current guidelines (e.g., Vanhatalo et al. 2015), relatively easy implementation, and the uncompromised drainage efficiency. Our simulations suggested, however, that these measures are ineffective on deep peat sites and that pits can even increase SS load (Table 2). The poor performance of sedimentation ponds on deep peat was expected based on literature (Manninen 1998, Joensuu et al. 1999), but the adverse effect of pits was a new finding. Whether the pits increase erosion in the manner proposed by our model should be assessed experimentally. If pits proved to be as poorly performing as proposed by our model, it would have significant implications to operational forestry in Finland, where pits are routinely implemented in the about 60000 ha of peatlands treated annually with DNM (Päivänen and Hånell 2012).

Our simulations suggested that the benefits of the sedimentation pond were limited to the period 
immediately after DNM (Fig. 8d), when flow rates were relatively low and SS concentrations high (see Haahti et al. 2016a). However, constructing a pond only to capture sediments during this initial stage would not be particularly cost-effective. The V-notch weir (Fig. 8c) behaved similarly to the pond whereas PRC, which performed better during later times, was less efficient in trapping the initial sediment load (Fig. 8h). To enhance the performance of PRC, the lower pipe of the structure could be sealed temporarily to increase sediment deposition during the time of low flow rates during and after DNM. Poor performance of PRC at this initial stage has not been reported in earlier experimental studies. However, many other common features with earlier studies were observed, including change in the form of the hydrograph (Amatya et al. 2003, Marttila et al. 2010), increased deposition (Marttila and Kløve 2010), and the highest reductions occurring during snowmelt (Kløve 2000).

Compared to sedimentation ponds and pits, the scenarios with structures aiming to decrease erosion (PRC, breaks in cleaning, submerged weir) reduced SS loads more efficiently (Table 2). Thus, sediment control on deep peat sites should rather focus on these structures than structures that aim to trap already eroded material. Forest managers may, however, be reluctant to implement PRC, breaks in cleaning, and submerged weirs fearing that drainage efficiency would be compromised. Based on our results, such concern is unwarranted in sites with low conductive deeper peat layers. The same conclusion was reported by Hökkä et al. (2011), who studied the effects of PRC on water table depth and tree growth. Also, the needed pipes or stones, unavailable on site, for constructing PRC structures or submerged weirs may influence the choice made by the forest manager. In this regard, breaks in cleaning are the easiest to implement among structures targeting erosion. However, their effect depends a lot on the state of the ditches before DNM, e.g., vegetation cover and depth.

The SS load reductions for the structures targeting erosion presented in Table 2 give an idea of their efficiency, but obviously are strongly site-dependent. For example, on a steeper site, PRC would not be able to retain flow as effectively protecting only a small part of the ditch network from erosion (e.g., Marttila et al. 2010). On such site, well-targeted breaks in cleaning within the ditch network would likely be more efficient. Basically, the efficient use of these structures comes down to 
recognizing the ditch sections sensitive to erosion. To facilitate practical planning, erosion risk maps generated by RL-GIS (Lauri and Virtanen 2002) have been made available for operational use and another tool to assess the ponding extent of PRC is under development. RL-GIS has been shown to identify erosion sensitive sections relatively well (Tuukkanen et al. 2012), but its performance with higher resolution topographic input data, made available by the National Land Survey of Finland in recent years, should be explored.

Compared to bed erosion occurring in distinct ditch sections, rain-induced erosion from banks taking place over the entire ditch network is more difficult to control. Among the structures assessed in this study, sedimentation ponds and pits have the potential to trap the material eroded from banks, but they proved to be ineffective. Controlling the SS load, which originates from bank erosion, thus calls for other measures. If the site is suitable for the construction of a wetland buffer area, this share of the load could plausibly be cut down efficiently (Sallantaus et al. 1998, Nieminen et al. 2005). Another possibility would be to adopt measures from peat harvesting where ponds are equipped with barrier structures (e.g., Mohammadighavam et al. 2015). Alternative methods for DNM, where disturbance of the ditch banks is minimized by special excavator scoops, should also be further explored (e.g., Hansen et al. 2013). Finally, it is highly important regarding SS load control to avoid DNM when it is unnecessary due to high stand evapotranspiration (Sarkkola et al. 2010) or unprofitable due to poor productivity of the site (Ahtikoski et al. 2012).

\section{Conclusions}

- The presented process-based modeling proved to be a powerful tool for comparing alternative sediment control practices after ditch network maintenance (DNM) on a forested peatland, supplementing experimentally gained knowledge and providing much-needed scientific basis for operational guidelines.

- Based on scenario simulations, sediment control on deep peat sites should focus on structures decreasing erosion rather than structures aiming to trap already eroded material. Especially 
sedimentation pits were ineffective or even harmful as they occasionally increased erosion.

- Structures raising ditch water level were shown to have marginal effects on water table levels in the peatland forest strips with poorly conductive subsoil between ditches, implying that drainage conditions and tree growth would not be compromised.

- The study highlighted the need to adapt operational level guidance for deep peat sites by reconsidering the recommendations for the implementation routines of sedimentation pits and ponds.

- The possibilities to trap peat eroded from the ditch banks with structures or measures, other than the ones investigated in this study, should be addressed in future studies, as well as increasing the efficiency of peak runoff control during and immediately after DNM.

\section{Acknowledgments}

Field data were collected by the Natural Resources Institute Finland, University of Oulu, and Aalto University. The Finnish Meteorological Institute and the National Land Survey of Finland are acknowledged for their open data. We thank Timo Hiltunen (Metsähallitus) for his insights on operational peatland forestry. This work was funded by Maa- ja vesitekniikan tuki ry.

\section{References}

Ahtiainen, M., and Huttunen, P. 1999. Long-term effects of forestry managements on water quality and loading in brooks. Boreal Environ. Res. 4: 101-114.

Ahtikoski, A., Salminen, H., Hökkä, H., Kojola, S., and Penttilä, T. 2012. Optimising stand management on peatlands: the case of northern Finland. Can. J. For. Res. 42(2): 247-259. doi:10.1139/x11-174.

Amatya, D.M., Skaggs, R.W., Gilliam, J.W., and Hughes, J.H. 2003. Effects of orifice-weir outlet on hydrology and water quality of a drained forested watershed. South. J. Appl. For. 27(2): 130142. doi:10.1579/0044-7447-33.4.228.

Andréasson, J., Bergström, S., Carlsson, B., Graham, L.P., and Lindström, G. 2004. Hydrological 
change - Climate change impact simulations for Sweden. Ambio 33(4-5): 228-234.

Finér, L., Mattsson, T., Joensuu, S., Koivusalo, H., Lauren, A., Makkonen, T., Nieminen, M., Tattari, S., Ahti, E., Kortelainen, P., Koskiaho, J., Leinonen, A., Nevalainen, R., Piirainen, S., Saarelainen, J., Sarkkola, S., and Vuollekoski, M. 2010. A method for calculating nitrogen, phosphorus and sediment load from forest catchments, The Finnish Environment, No. 10. Finnish Environment Institute, Helsinki, Finland.

Haahti, K., Marttila, H., Warsta, L., Kokkonen, T., Finér, L., and Koivusalo, H. 2016a. Modeling sediment transport after ditch network maintenance of a forested peatland. Water Resour. Res. 52(11): 9001-9019. doi:10.1002/2016WR019442.

Haahti, K., Warsta, L., Kokkonen, T., Younis, B.A., and Koivusalo, H. 2016b. Distributed hydrological modeling with channel network flow of a forestry drained peatland site. Water Resour. Res. 52(1): 246-263. doi:10.1002/2015WR018038.

Hamill, L. 2001. Understanding Hydraulics. In 2nd edition. Palgrave, Basingstoke, UK.

Hansen, K., Kronnäs, V., Zetterberg, T., Setterberg, M., Moldan, F., Pettersson, P., and Munthe, J. 2013. DiVa - dikesrensningens effekter på vattenföring, vattenkemi och bottenfauna i skogsekosystem. IVL Svenska Miljöinstitutet AB, Göteborg, Sweden.

Hökkä, H., Alenius, V., and Salminen, H. 2000. Predicting the need for ditch network maintenance in drained peatland sites in Finland. Suo 51(1): 1-10.

Hökkä, H., Hyttinen, H., Marttila, H., Jämsen, J., and Kløve, B. 2011. Effect of peak runoff control method on growth of Scots pine stands on drained peatlands in central Finland. Silva Fenn. 45(3): 331-339. doi:10.14214/sf.106.

Holden, J., Gascoign, M., and Bosanko, N.R. 2007. Erosion and natural revegetation associated with surface land drains in upland peatlands. Earth Surf. Process. Landf. 32(10): 1547-1557. doi:10.1002/esp. 1476 .

Joensuu, S., Ahti, E., and Vuollekoski, M. 1999. The effects of peatland forest ditch maintenance on suspended solids in runoff. Boreal Environ. Res. 4(4): 343-356. 
Joensuu, S., Ahti, E., and Vuollekoski, M. 2002. Effects of ditch network maintenance on the chemistry of run-off water from peatland forests. Scand. J. For. Res. 17(3): 238-247. doi:10.1080/028275802753742909.

Joensuu, S., Kauppila, M., Lindén, M., and Tenhola, T. 2012. Hyvän metsänhoidon suositukset Vesiensuojelu. Tapio Oy, Helsinki, Finland.

Kløve, B. 2000. Retention of suspended solids and sediment bound nutrients from peat harvesting sites with peak runoff control, constructed floodplains and sedimentation ponds. Boreal Environ. Res. 5(1): 81-94.

Koivusalo, H., Kokkonen, T., Laurén, A., Ahtiainen, M., Karvonen, T., Mannerkoski, H., Penttinen, S., Seuna, P., Starr, M., and Finér, L. 2006. Parameterisation and application of a hillslope hydrological model to assess impacts of a forest clear-cutting on runoff generation. Environ. Model. Softw. 21(9): 1324-1339. doi:10.1016/j.envsoft.2005.04.020.

Lauri, H., and Virtanen, M. 2002. A decision support system for management of boreal river catchments. Large Rivers 13(3-4): 401-408. doi:10.1127/lr/13/2002/401.

Lin, Q., and Wu, W. 2013. A one-dimensional model of mixed cohesive and non-cohesive sediment transport in open channels. J. Hydraul. Res. 51(5), 506-517. doi:10.1080/00221686.2013.812046.

Manninen, P. 1998. Effects of forestry ditch cleaning and supplementary ditching on water quality. Boreal Environ. Res. 3(1): 23-32.

Marttila, H., and Kløve, B. 2010. Managing runoff, water quality and erosion in peatland forestry by peak runoff control. Ecol. Eng. 36(7): 900-911. doi:10.1016/j.ecoleng.2010.04.002.

Marttila, H., Vuori, K.-M., Hökkä, H., Jämsen, J., and Kløve, B. 2010. Framework for designing and applying peak runoff control structures for peatland forestry conditions. For. Ecol. Manag. 260(8): 1262-1273. doi:10.1016/j.foreco.2010.06.032.

Mohammadighavam, S., Heiderscheidt, E., Marttila, H., and Kløve, B. 2015. Optimization of gravitydriven hydraulic flocculators to treat peat extraction runoff water. J. Irrig. Drain. Eng. 142(2): 
04015045. doi:10.1061/(ASCE)IR.1943-4774.0000955.

Nieminen, M., Ahti, E., Nousiainen, H., Joensuu, S., and Vuollekoski, M. 2005. Capacity of riparian buffer zones to reduce sediment concentrations in discharge from peatlands drained for forestry. Silva Fenn. 39(3): 331-339. doi:10.14214/sf.371.

Päivänen, J., and Hånell, B. 2012. Peatland Ecology and Forestry - a Sound Approach. University of Helsinki Department of Forest Sciences Publication 3, Helsinki, Finland.

Päivinen, J., Björkqvist, N., Karvonen, L., Kaukonen, M., Korhonen, K.-M., Kuokkanen, P., Lehtonen, H., and Tolonen (Editors). 2011. Metsähallituksen metsätalouden ympäristöopas. Metsähallitus, Vantaa, Finland.

Pavey, B., Saint-Hilaire, A., Courtenay, S., Ouarda, T., and Bobée, B. 2007. Exploratory study of suspended sediment concentrations downstream of harvested peat bogs. Environ. Monit. Assess. 135(1-3): 369-382. doi:10.1007/s10661-007-9656-8.

Prévost, M., Plamondon, A.P., and Belleau, P. 1999. Effects of drainage of a forested peatland on water quality and quantity. J. Hydrol. 214(1): 130-143. doi:10.1016/S0022-1694(98)00281-9.

Ramchunder, S.J., Brown, L.E., and Holden, J. 2009. Environmental effects of drainage, drainblocking and prescribed vegetation burning in UK upland peatlands. Prog. Phys. Geogr. 33(1): 49-79. doi:10.1177/0309133309105245.

Ring, E., Löfgren, S., Sandin, L., Högblom, L., Goedkoop, W., Bergqvist, I., and Berg, S. 2008. Skogsbruk med hänsyn till vatten - en handledning från Skogforsk. Skogforsk, Sundbyberg, Sweden.

Robinson, M., and Blyth, K. 1982. The effect of forestry drainage operations on upland sediment yields: a case study. Earth Surf. Process. Landf. 7(1): 85-90. doi:10.1002/esp.3290070111.

Sallantaus, T., Vasander, H., and Laine, J. 1998. Prevention of detrimental impacts of forestry operations on water bodies using buffer zones created from drained peatlands. Suo 49(4): 125 133.

Samson-Dô, M. 2015. Caractérisation et modélisation de l'efficacité de bassins de sédimentation en 
aval de tourbières exploitées. Master's Thesis, Université du Québec, Institut National de la Recherche Scientifique, Québec, Canada.

Sarkkola, S., Hökkä, H., Koivusalo, H., Nieminen, M., Ahti, E., Päivänen, J., and Laine, J. 2010. Role of tree stand evapotranspiration in maintaining satisfactory drainage conditions in drained peatlands. Can. J. For. Res. 40(8): 1485-1496. doi:10.1139/X10-084.

Seuna, P. 1983. Small basins: a tool in scientific and operational hydrology. National Board of Waters, Finland.

Tuukkanen, T., Koivusalo, H., Marttila, H., Leinonen, A., Kløve, B., Laurén, A., and Finér, L. 2012. A GIS-based model for ditch erosion risk assessment in peatland forestry. In Proceedings of a symposium held at the Institute of Mountain Hazards and Environment, CAS-Chengdu, China, 11-15 October 2012.

Vaché, K.B., Eilers, J.M., and Santelmann, M.V. 2002. Water quality modeling of alternative agricultural scenarios in the U.S. Corn Belt. J. Am. Water Resour. Assoc. 38(3): 773-787. doi:10.1111/j.1752-1688.2002.tb00996.x.

Vanhatalo, K., Väisänen, P., Joensuu, S., Sved, J., Koistinen, A., and Äijälä, O. (Editors). 2015. Metsänhoidon suositukset suometsien hoitoon, työopas. Tapio Oy, Helsinki, Finland.

Warsta, L., Karvonen, T., Koivusalo, H., Paasonen-Kivekäs, M., and Taskinen, A. 2013. Simulation of water balance in a clayey, subsurface drained agricultural field with three-dimensional FLUSH model. J. Hydrol. 476: 395-409. doi:10.1016/j.jhydrol.2012.10.053. 
Table 1. Number of values included in the frequency distributions of investigated variables for scenarios in Figs. 4b-g

\begin{tabular}{lccc}
\hline \multirow{2}{*}{ Scenario } & \multicolumn{3}{c}{$\begin{array}{c}\text { Number of values included in distributions of } \\
\text { variables (spatial units } \times \text { time-steps) }\end{array}$} \\
\cline { 2 - 4 } & $\begin{array}{c}\text { Discharge at } \\
\text { outlet }\end{array}$ & $\begin{array}{c}\text { Flow velocity or } \\
\text { ditch water level* }\end{array}$ & $\begin{array}{c}\text { Water table } \\
\text { level }\end{array}$ \\
\hline V-notch & $1 \times 8748$ & $177(1) \times 8748$ & $2220 \times 8748$ \\
Pond & $1 \times 8748$ & $180(3) \times 8748$ & $2220 \times 8748$ \\
Pits 1 & $1 \times 8748$ & $191(8) \times 8748$ & $2220 \times 8748$ \\
Break & $1 \times 8748$ & $179(3) \times 8748$ & $2220 \times 8748$ \\
SWeir & $1 \times 8748$ & $180(2) \times 8748$ & $2220 \times 8748$ \\
PRC & $1 \times 8748$ & $177(1) \times 8748$ & $2220 \times 8748$ \\
\hline
\end{tabular}

*Number of nodes at the location of the structures in parentheses 
Table 2. SS load reductions for the first year after DNM for scenarios in Figs. 4b-p

\begin{tabular}{lc}
\hline Scenario & $\begin{array}{c}\text { SS load reduction }(\%) \\
\text { median }(\min . . \mathrm{max})^{*}\end{array}$ \\
\hline V-notch & $18.8(10.9 \ldots 27.0)$ \\
Pond & $6.4(1.6 \ldots 15.2)$ \\
Pits 1 & $-10.3(-17.4 \ldots-4.1)$ \\
Break & $16.5(4.5 \ldots 30.6)$ \\
SWeir & $30.1(16.4 \ldots 45.9)$ \\
PRC & $25.9(15.2 \ldots .40 .4)$ \\
Pits 2 & $-13.3(-21.1 \ldots-4.1)$ \\
Breaks & $23.5(15.1 \ldots 32.0)$ \\
Pond-SWeir & $10.8(3.4 \ldots 19.7)$ \\
Pond-PRC & $27.8(16.0 \ldots 44.4)$ \\
Pits-Breaks & $12.9(8.7 \ldots 18.1)$ \\
Pit-Break & $16.4(4.4 \ldots 30.6)$ \\
Pit-SWeir & $30.1(16.3 \ldots 45.9)$ \\
Pit-PRC & $26.2(15.3 \ldots 40.8)$ \\
Break-Pond-PRC & $34.2(19.3 \ldots . .52 .2)$ \\
\hline *Resulting from the 100 SS transport model runs
\end{tabular}


Fig. 1. (a) Location of the study site in Finland, (b) the Koivupuro catchment, and (c) the studied catchment.

Fig. 2. Longitudinal profile of ditch bottom (left) and cross-section (right) for (a) the sedimentation pond, (b) the sedimentation pit, (c) the break in cleaning, and (d) the submerged weir. All dimensions are in scale except for the ones indicated with arrows. The length of the break in cleaning $(L)$ and the height of the submerged weir $\left(h_{\text {weir }}\right)$ were given different values depending on the scenario.

Fig. 3. (a) Schematic figure of peak runoff control structure and (b) rating curve of the selected pipe setup showing pipes as gray areas.

Fig. 4. Structure locations within the ditch network of the catchment in (a) the baseline scenario, (b) the prevailing setup after DNM, and (c-p) the sediment control scenarios. $L$ is the length of the break in cleaning and $h_{\text {weir }}$ is the weir height. For other structure dimensions see Fig. 2. The downstream boundary condition of the ditch network flow model (eq. (1), (2) or Fig. 3b depending on structure) was defined at the catchment outlet for the scenarios $(b, g, j, k, 0, p)$ and further downstream for the others as shown in (a).

Fig. 5. Frequency distributions of outlet discharge, flow velocity, ditch water level, and water table level for scenarios (a-d) V-notch, (e-h) Pond, (i-l) Pits1, (m-p) Break, (q-t) SWeir, and (u-x) PRC; and changes in frequencies compared to the Baseline scenario. The reference elevation of ditch water and water table level is the soil surface. See Figs. $4 \mathrm{~b}-\mathrm{g}$ for scenario details.

Fig. 6. Spatial change in water table level $(\mathrm{mm})$ and ditch water level (m) for scenarios (a-b) V-notch, (c-d) Pond, (e-f) Pits1, (g-h) Break, (i-j) SWeir, and (k-l) PRC compared to the Baseline scenario. Left panes show mean changes during 15-Jun-2012 to 15-Aug-2012 and right panes during a rainfall event on 7-Aug-2012. Absolute water table level changes $<0.0025$ mm are not shown. See Figs. 4 b-g for scenario details. Print colors Fig. 7. Sediment mobility in (a) the Baseline scenario for the first year after DNM, and effects of scenarios on (b) SS load, (c) bed erosion, (d) rain-induced bank erosion, and (e) deposition compared to the Baseline scenario. Error bars denote the 5 to $95 \%$ range resulting from the 100 SS transport model runs. See Fig. 4 for scenario details.

Fig. 8. (a) Cumulative main water balance components for the catchment, (b) SS load for the Baseline scenario, and (c-q) efficiency of scenarios in reducing SS loads during the first year after DNM. Results presented as ranges from the $100 \mathrm{SS}$ transport model runs. See Fig. 4 for scenario details. 


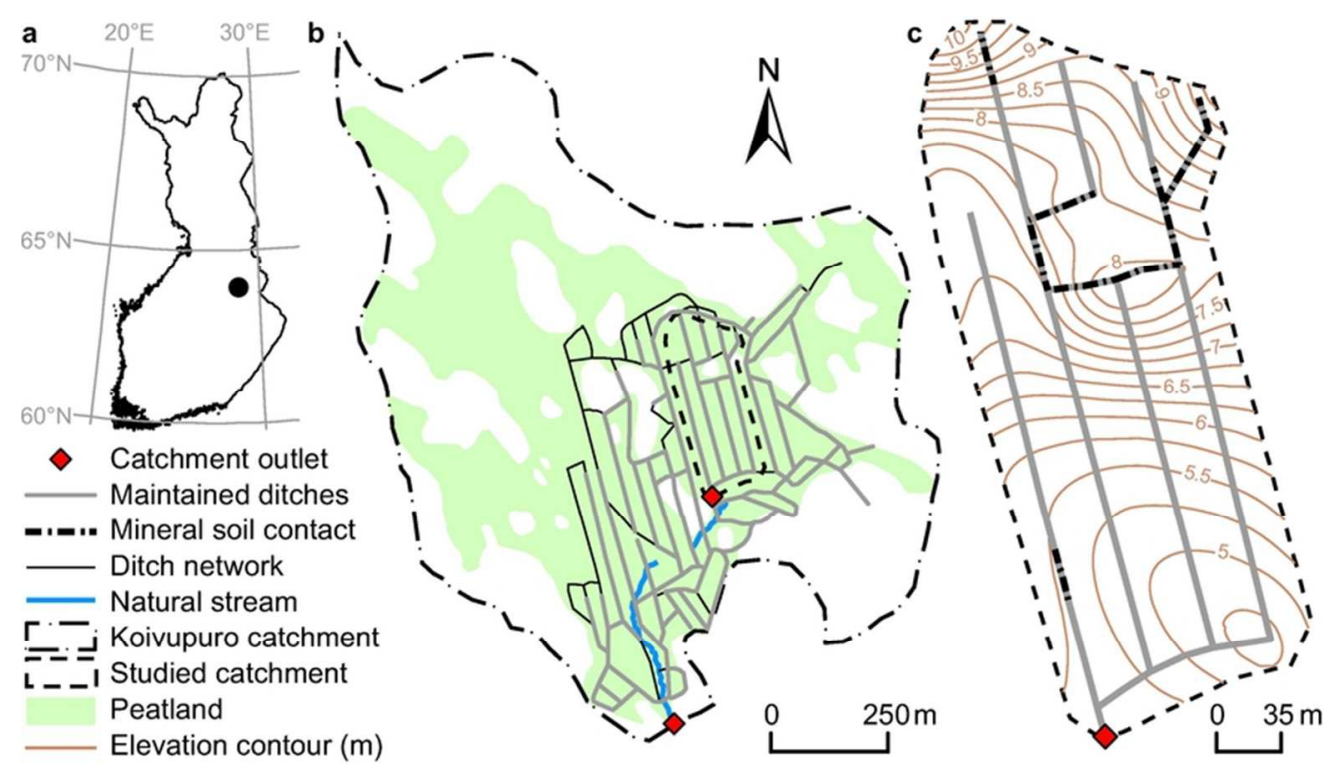

Fig. 1. (a) Location of the study site in Finland, (b) the Koivupuro catchment, and (c) the studied catchment.

$73 \times 42 \mathrm{~mm}(300 \times 300 \mathrm{DPI})$ 
a
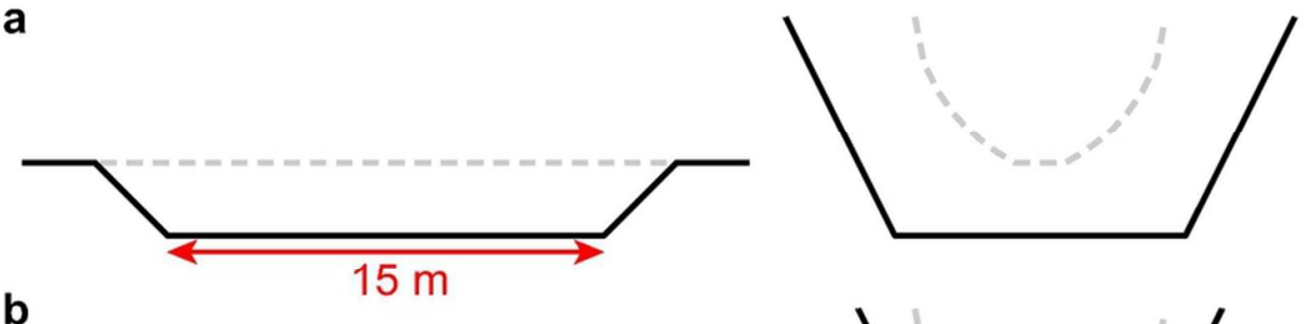

b
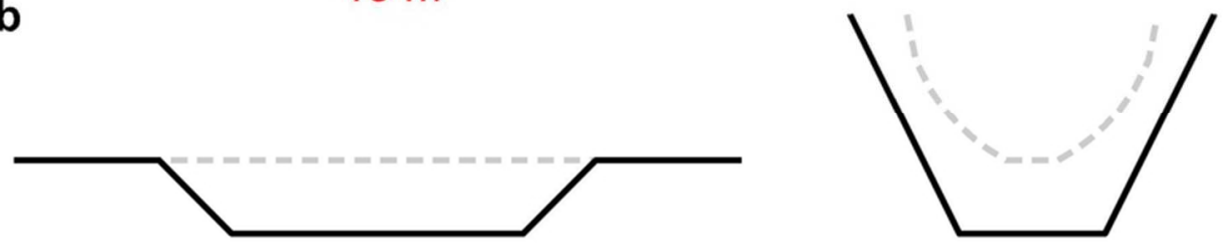

C
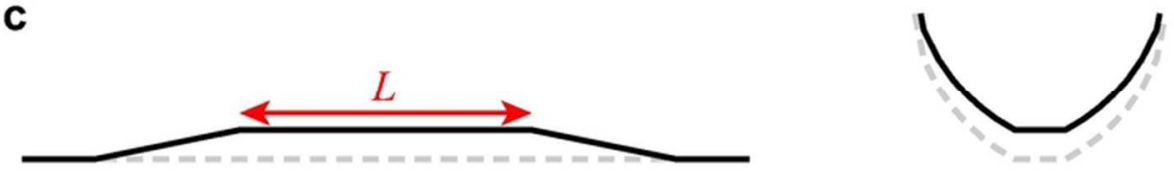

d

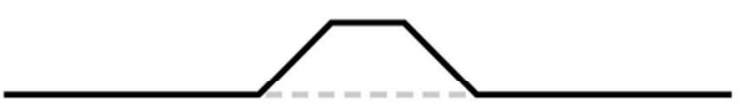

Sediment control structure

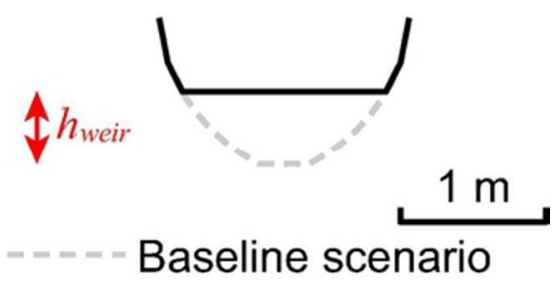

Fig. 2. Longitudinal profile of ditch bottom (left) and cross-section (right) for (a) the sedimentation pond, (b) the sedimentation pit, (c) the break in cleaning, and (d) the submerged weir. All dimensions are in scale except for the ones indicated with arrows. The length of the break in cleaning $(L)$ and the height of the submerged weir (hweir) were given different values depending on the scenario.

$69 \times 58 \mathrm{~mm}(300 \times 300 \mathrm{DPI})$ 

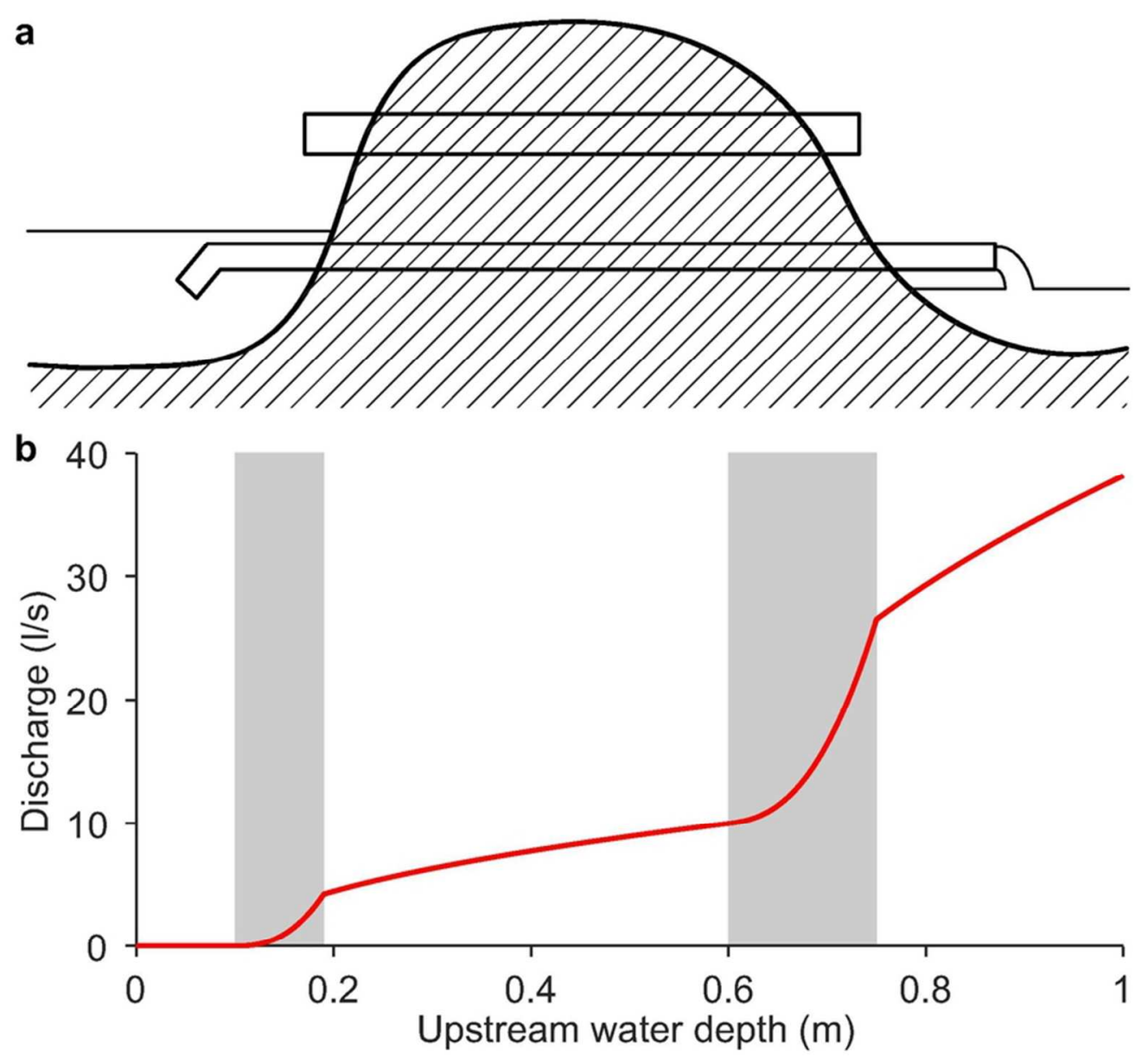

Fig. 3. (a) Schematic figure of peak runoff control structure and (b) rating curve of the selected pipe setup showing pipes as gray areas.

$77 \times 72 \mathrm{~mm}(300 \times 300 \mathrm{DPI})$ 


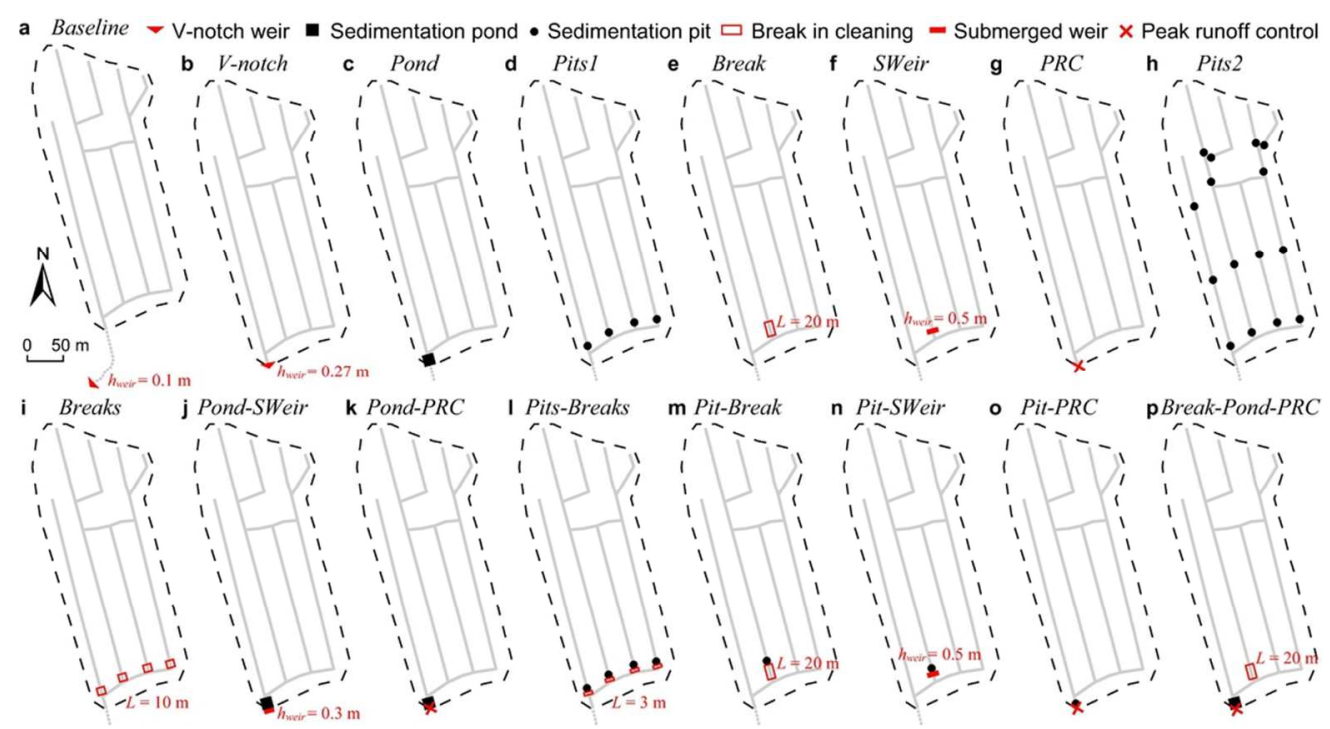

Fig. 4. Structure locations within the ditch network of the catchment in (a) the baseline scenario, (b) the prevailing setup after DNM, and (c-p) the sediment control scenarios. $L$ is the length of the break in cleaning and hweir is the weir height. For other structure dimensions see Fig. 2 . The downstream boundary condition

of the ditch network flow model (eq. (1), (2) or Fig. 3b depending on structure) was defined at the catchment outlet for the scenarios $(b, g, j, k, 0, p)$ and further downstream for the others as shown in (a).

$$
94 \times 51 \mathrm{~mm}(300 \times 300 \mathrm{DPI})
$$




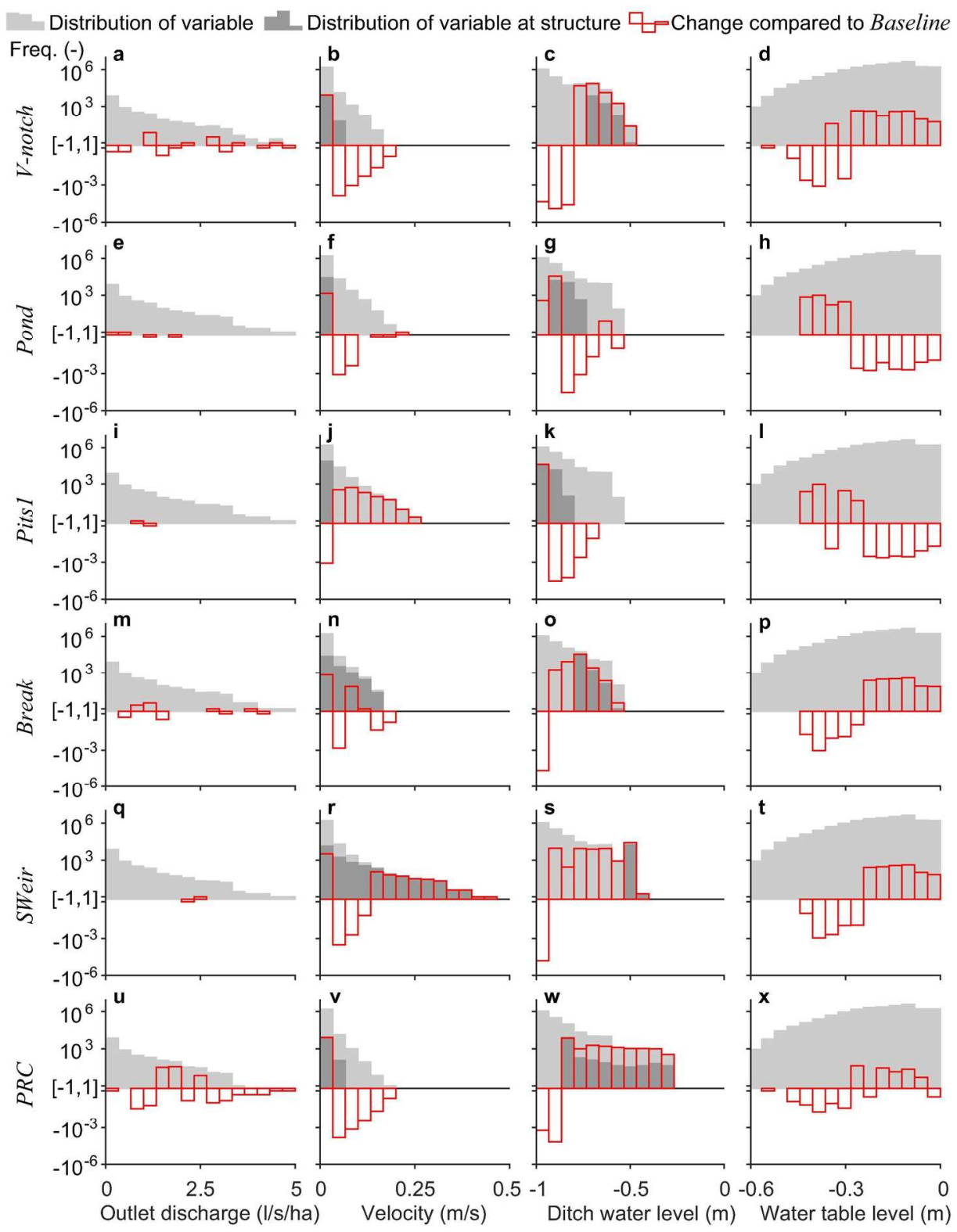

Fig. 5. Frequency distributions of outlet discharge, flow velocity, ditch water level, and water table level for scenarios (a-d) V-notch, (e-h) Pond, (i-I) Pits1, (m-p) Break, ( $q-t)$ SWeir, and ( $u-x)$ PRC; and changes in frequencies compared to the Baseline scenario. The reference elevation of ditch water and water table level is the soil surface. See Figs. $4 \mathrm{~b}-\mathrm{g}$ for scenario details.

$166 \times 214 \mathrm{~mm}(300 \times 300 \mathrm{DPI})$ 

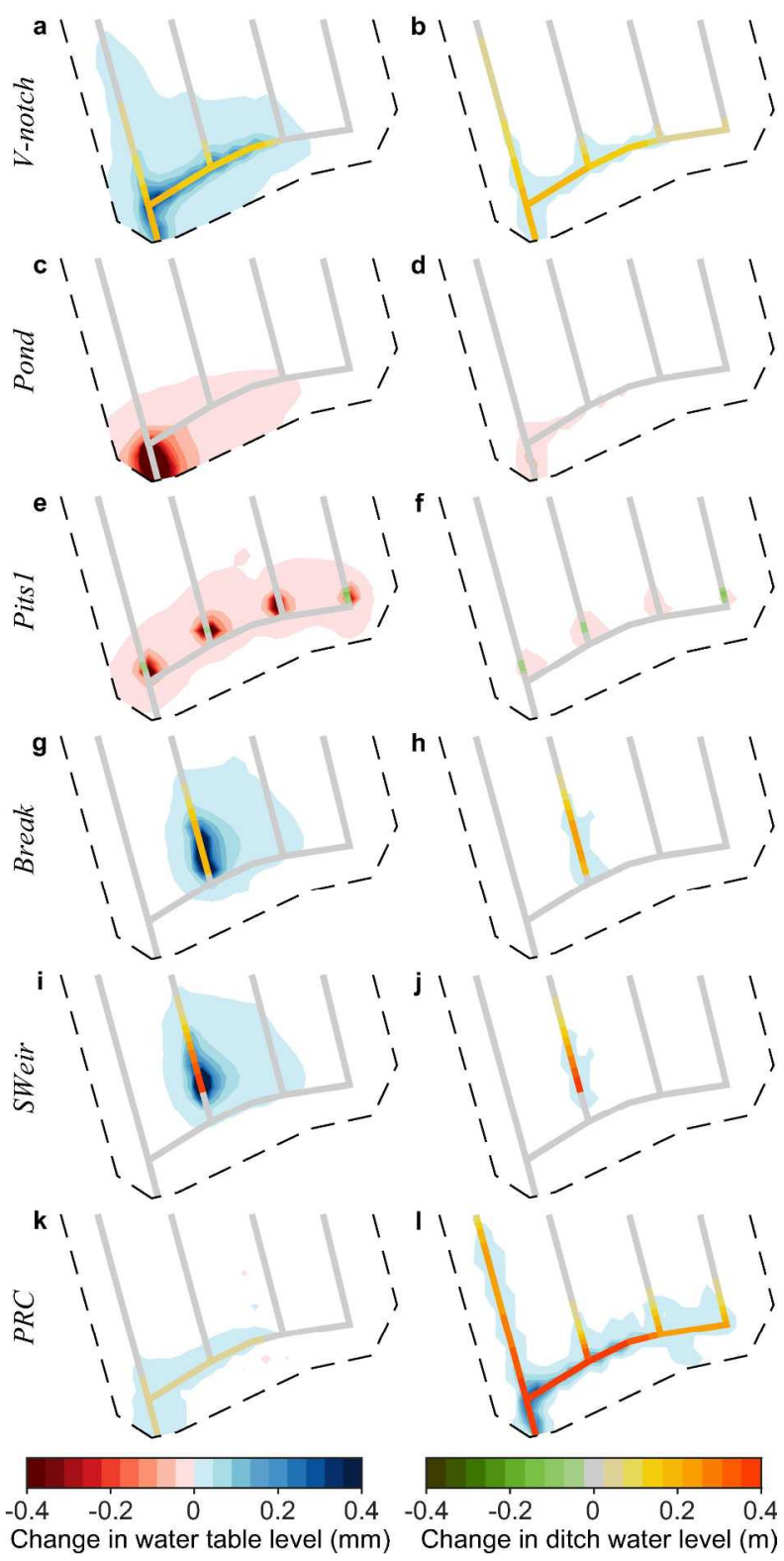

Fig. 6. Spatial change in water table level $(\mathrm{mm})$ and ditch water level $(\mathrm{m})$ for scenarios (a-b) V-notch, (c-d) Pond, (e-f) Pits1, ( $g-h)$ Break, (i-j) SWeir, and (k-l) PRC compared to the Baseline scenario. Left panes show mean changes during 15-Jun-2012 to 15-Aug-2012 and right panes during a rainfall event on 7-Aug-2012. Absolute water table level changes $<0.0025 \mathrm{~mm}$ are not shown. See Figs. $4 \mathrm{~b}-\mathrm{g}$ for scenario details.

$168 \times 337 \mathrm{~mm}(300 \times 300 \mathrm{DPI})$ 


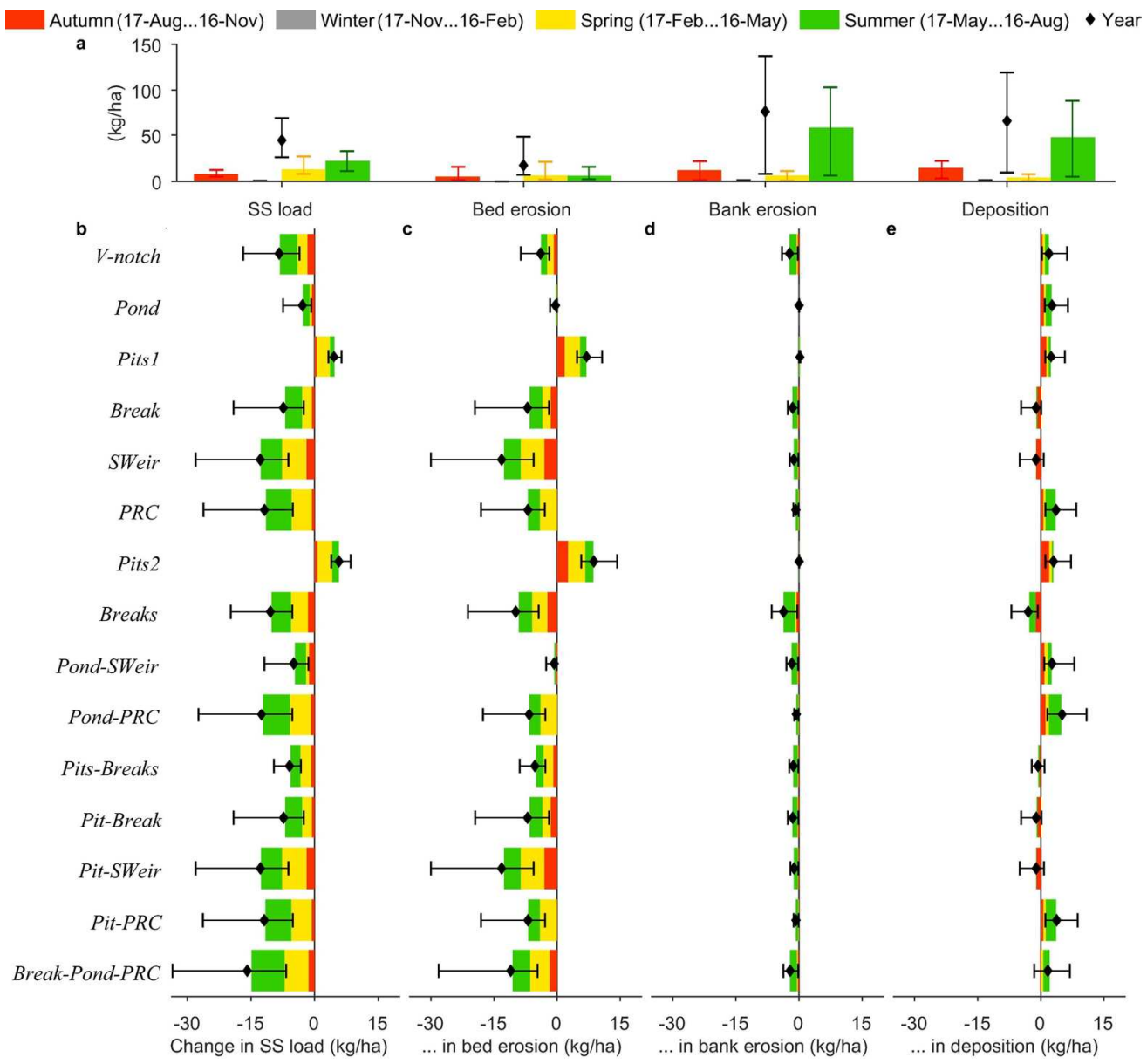

Fig. 7. Sediment mobility in (a) the Baseline scenario for the first year after DNM, and effects of scenarios on (b) SS load, (c) bed erosion, (d) rain-induced bank erosion, and (e) deposition compared to the Baseline scenario. Error bars denote the 5 to $95 \%$ range resulting from the $100 \mathrm{SS}$ transport model runs. See Fig. 4 for scenario details.

$159 \times 147 \mathrm{~mm}(300 \times 300$ DPI $)$ 


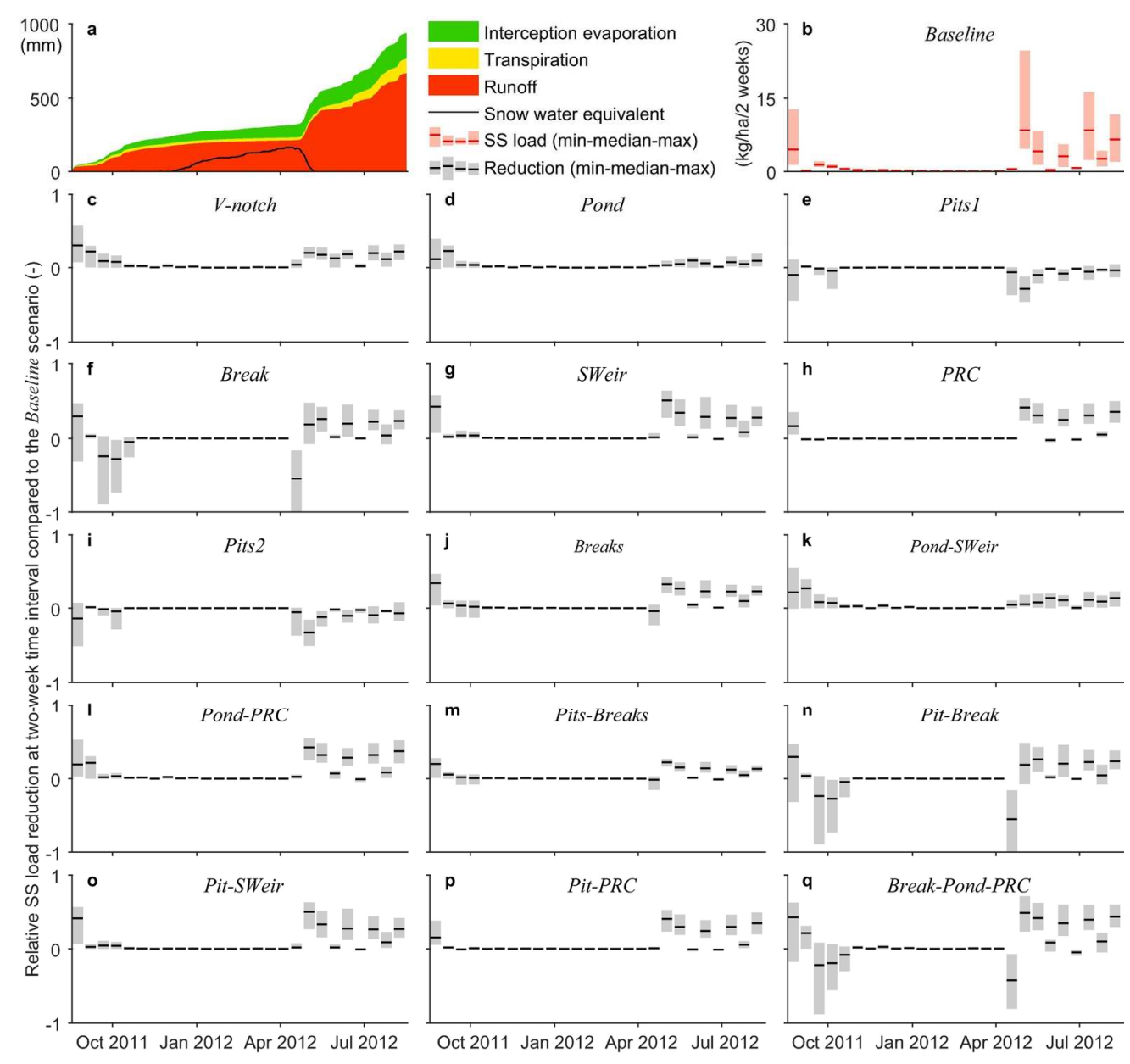

Fig. 8. (a) Cumulative main water balance components for the catchment, (b) SS load for the Baseline scenario, and (c-q) efficiency of scenarios in reducing SS loads during the first year after DNM. Results presented as ranges from the 100 SS transport model runs. See Fig. 4 for scenario details.

$162 \times 153 \mathrm{~mm}(300 \times 300$ DPI $)$ 